\title{
Group Cognitive Therapy For Suicide Prevention Berbasis Internet Untuk Mengurangi Ide Bunuh Diri Pada Mahasiswa
}

\section{Internet-based Group Cognitive Therapy For Suicide Prevention (CT- SP) To Reduce Suicide Ideation Among College Students}

\author{
Puput Mariyati ${ }^{(1 *)} \& \operatorname{Hamidah}^{(2)}$ \\ Fakultas Psikologi, Universitas Airlangga, Indonesia \\ Disubmit: 10 Januari 2021; Diproses: 21 April 2021; Diaccept: 01 September 2021; Dipublish: 02 Desember 2021 \\ *Corresponding author: E-mail: mariyati.puput@gmail.com
}

\begin{abstract}
Abstrak
Penelitian ini bertujuan untuk menguji efektivitas Cognitive Therapy for Suicide Prevention (CT-SP) berbasis internet dengan pendekatan kelompok untuk mengurangi ide bunuh diri pada mahasiswa. Mahasiswa mengalami masa yang menantang saat memasuki jenjang pendidikan tinggi karena transisi perkembangan dari remaja akhir menuju dewasa awal. Dalam masa transisi ini, mahasiswa mungkin mengalami tekanan atau masalah psikologis yang menjadi faktor resiko terkait ide bunuh diri. Wenzel et al., (2009) mendefinisikan ide bunuh diri sebagai pikiran, gambar, keyakinan, suara, atau kognisi lain yang dilaporkan oleh individu untuk mengakhiri hidupnya sendiri. CT-SP menunjukkan efektivitas dalam menurunkan ide bunuh diri, namun untuk pendekatan online belum diketahui. Desain penelitian yang digunakan adalah kelompok kontrol pretest posttest. Subjek adalah mahasiswa yang berstatus aktif di perguruan tinggi negeri dan swasta yang berusia 18-25 tahun. Subyek berjumlah 14 orang yang dibagi dalam kelompok ekperimen dan kelompok kontrol. Instrumen yang digunakan adalah Scale of Suicidal Ideation (Beck et al., 1979). Hasil penelitian menunjukkan perbedaan skor ide bunuh diri pada kelompok perlakuan dan kelompok kontrol sebelum dan sesudah diberikan intervensi, dengan sig. 0.011 (sig.< 0,05) dan nilai effect size 1.595 (kategori efektivitas besar). Dengan demikian, dapat disimpulkan bahwa intervensi CT-SP berbasis internet dengan pendekatan kelompok efektif dalam menurunkan ide bunuh diri mahasiswa.
\end{abstract}

Kata Kunci: Cognitive Therapy For Suicide Prevention; Ide Bunuh Diri; Intervensi Berbasis Internet

\begin{abstract}
This study aims to analyze the effectiveness of internet-based group Cognitive Therapy for Suicide Prevention (CT-SP) to reduce suicidal ideation among college students. College students experienced a challenging period when entering higher education because of the transition from late adolescence to early adulthood. During this period, they may experience psychological stress or mental health problems which are risk factors in suicidal ideation. Wenzel et al., (2009) define suicidal ideation as thoughts, images, beliefs, sounds, or other cognitions reported by individuals to complete their own lives. CT-SP has shown power in reducing suicidal ideation, but the online approach is unknown. The research used a pretest posttest control group design. Subjects are students who study in public or private university aged 18-25 years. Subjects were 14 people who were divided into experimental and control group. The instrument used was the Scale of Suicidal Ideation (Beck et al., 1979). The results showed differences in the scores of suicide ideation between experimental group and control group before and after the intervention with sig. 0.011 (sig. $<0.05)$ and the effect size value is 1.595 with a large category. Thus, online CT-SP intervention is effective in reducing suicidal ideation among college students.
\end{abstract}

Keywords: Cognitive Therapy For Suicide Prevention; Suicidal Ideation; Online Intervention

How to Cite: Mariyati, P., \& Hamidah. (2021). Group Cognitive Therapy For Suicide Prevention Berbasis Internet Untuk Mengurangi Ide Bunuh Diri Pada Mahasiswa, Jurnal Diversita, 7 (2): 201-210. 


\section{PENDAHULUAN}

Memasuki jenjang pendidikan tinggi merupakan transisi kehidupan yang menantang bagi mahasiswa. Banyak tantangan yang harus dihadapi, baik dari akademik, perkembangan, social budaya maupun ekonomi. Dari segi akademik, mahasiswa dituntut untuk mengembangkan potensi secara aktif dengan melakukan pembelajaran, pencarian kebenaran ilmiah, penguasaan dan pengamalan Ilmu Pengetahuan dan/atau Teknologi untuk menjadi ilmuwan/praktisi/profesional yang berbudaya dan mengutamakan penalaran dan akhlak mulia. Mahasiswa wajib menyusun tugas akhir dan publikasi di jurnal ilmiah nasional atau internasional yang terakreditasi. Hal ini tercantum dalam UU No.12 Tahun 2012 dan Peraturan Menteri Riset, Teknologi, dan Pendidikan Tinggi Nomor 50 Tahun 2018.

Dari segi perkembangan, mahasiswa umumnya berumur 18-30 tahun (Sarwono, 2012). Rentang umur ini berada di antara masa remaja akhir dan masa dewasa awal. Transisi umur pada akhir remaja sampai dua puluhan (18-25 tahun) disebut sebagai emerging adulthood. Pada masa emerging adulthood, individu mulai bekerja dan menjalin hubungan dengan lawan jenis, ingin memiliki kebebasan dalam pengambilan keputusan tentang karir, relasi sosial dan keluarga, nilai dan pola hidup. Mereka melanjutkan ke pendidikan tinggi atau mengikuti pelatihan yang akan menjadi landasan bagi pekerjaan dan prestasi karier dewasa mereka (Arnett, 2000).

Dari segi ekonomi, individu pada masa dewasa muda mengharapkan adanya kemandirian secara finansial dan rasa tanggung jawab terhadap tindakantindakan yang dilakukan (Lemme, 1995). Dari segi sosial, individu pada masa ini mengalami penyesuaian terhadap pola kehidupan dan harapan sosial sehingga rentan menghadapi masalah pribadi dan lingkungan. Penyesuaian ini berhubungan dengan identitas diri, kemandirian, situasi dan kondisi di rumah, lingkungan sosial, serta hak dan kewajiban yang diperoleh orangtua dan orang-orang di sekitar. Dalam konteks ini, mahasiswa mungkin mengalami tekanan atau masalah psikologis terkait peran mereka di perguruan tinggi.

\section{Hunt \& Eisenberg} menjelaskan bahwa masalah kesehatan mental terjadi di kalangan mahasiswa dengan stressor hubungan, dukungan sosial rendah, atau korban kekerasan seksual. Mahasiswa perempuan lebih cenderung mengalami depresi berat dan gangguan kecemasan, sedangkan mahasiswa pria berisiko lebih tinggi untuk bunuh diri. Survei melaporkan bahwa di antara 8.155 siswa, 6,7\% melaporkan keinginan bunuh diri, 1,6\% melaporkan memiliki rencana bunuh diri, dan 0,5\% melaporkan pernah mencoba bunuh diri (Downs \& Eisenberg, 2012).

Di Indonesia, terdapat sebuah survei yang dilakukan tahun 2019 pada mahasiswa semester awal perguruan tinggi di Bandung. Hasilnya ditemukan $30,5 \%$ mahasiswa depresi, $20 \%$ berpikir serius bunuh diri, dan 6\% telah mencoba bunuh diri seperti cutting, gantung diri, atau loncat dari ketinggian (Kompas Online, 2019).

Merujuk analisis berita tentang kasus bunuh diri dari tahun 2015-2020 dari beragam kanal, penulis menemukan 19 
kasus bunuh diri di kalangan mahasiswa Indonesia. Beberapa penyebab yang terkait dengan kasus bunuh diri adalah permasalahan perkuliahan, kesulitan menyelesaikan tugas akhir, permasalahan dalam hubungan dengan pacar, keluarga dan teman.

Bunuh diri di kalangan mahasiswa memiliki etiologi yang unik karena transisi perkembangan yang terjadi di perguruan tinggi dan dewasa muda (Arria et al., 2009). Ide bunuh diri dikaitkan dengan fungsi psikososial yang buruk, depresi masa depan, dropout, perilaku seksual berisiko, perilaku agresif, dan penggunaan zat dan obat-obatan. Kurangnya dukungan sosial dari keluarga dan teman adalah korelasi penting dari ide bunuh diri remaja, dewasa, dan mahasiswa (Harris \& Molock, 2000). Faktor kontribusi potensial lainnya adalah disregulasi afeksi (Tarter et al., 2004).

Banyak kajian yang meneliti fenomena bunuh diri dengan beragam terminologi, seperti suicide, suicide attempt, dan suicide ideation. Menurut Crosby (2007, dalam Wenzel et al., 2009), bunuh diri merupakan kematian yang disebabkan oleh diri sendiri. Konsep lain yang penting dalam meninjau bunuh diri adalah upaya bunuh diri. Upaya bunuh diri adalah perilaku nonfatal, merugikan dan berpotensi membahayakan diri sendiri dengan niat untuk mati. Niat untuk mati dinyatakan secara langsung oleh orang tersebut untuk mengakhiri hidupnya sendiri atau dinyatakan secara tidak langsung dengan disimpulkan dari keadaan perilaku atau keyakinan seseorang bahwa perilaku tersebut bisa mengakibatkan kematian.
Centers for Disease Control and Prevention (dalam Klonsky et al., 2016) mengartikan ide bunuh diri adalah memikirkan, mempertimbangkan, atau merencanakan bunuh diri. Wenzel et al., (2009) mendefinisikan ide bunuh diri sebagai pikiran, gambar, keyakinan, suara, atau kognisi lain yang dilaporkan oleh individu untuk mengakhiri hidupnya sendiri. Saat individu mengalami episode intens ide bunuh diri yang disertai dengan keinginan atau percobaan bunuh diri, maka mereka sedang mengalami krisis bunuh diri. Ide bunuh diri mendahului upaya bunuh diri dan menjadi komponen utama dari tindakan bunuh diri dan prediktor kuat dari upaya bunuh diri (Wenzel et al., 2009).

Ide bunuh diri menjadi titik sentral yang mengarahkan individu untuk terlibat dalam upaya atau tindakan bunuh diri. Wenzel \& Beck (2008) mengembangkan model kognitif untuk memahami bagaimana dinamika ide bunuh diri dalam mempengaruhi dan mengarahkan individu untuk melakukan upaya atau tindakan bunuh diri. Proses kognitif terkait dengan bunuh diri dipicu saat skema bunuh diri diaktifkan. Skema kognitif diaktifkan dari tiga variabel, yaitu faktor kerentanan disposisional, kognisi terkait dengan gangguan kejiwaan, dan stres kehidupan. Ada dua skema bunuh diri yang juga terkait, yaitu keputusasaan dan persepsi tak tertahankan. Ide bunuh diri muncul karena ada kombinasi keputusasaan, pemrosesan informasi yang bias terkait bunuh diri dan fiksasi perhatian sehingga bunuh diri dianggap sebagai satu-satunya solusi untuk kesusahan atau permasalahan. 
Banyak peneliti melakukan studi tentang intervensi untuk mengurangi perilaku atau ide bunuh diri. Stanley et al., (2009) mengembangkan Cognitive Behavioral Therapy Suicide Prevention (CBT-SP) untuk mengurangi risiko upaya di masa depan pada remaja yang barubaru ini mencoba bunuh diri. DBT juga terbukti efektif untuk perilaku bunuh diri, namun sebagian besar terbatas pada sampel wanita (Jobes et al., 2015). Collaborative Assessment and Management of Suicidality (CAMS) juga termasuk intervensi terapi khusus bunuh diri yang banyak digunakan pada setting rumah sakit untuk stabilisasi pasien rawat jalan (Jobes et al., 2015).

Wenzel et al., (2009) mengembangkan Cognitive Therapy for Suicidal Prevention (CT-SP) sebagai terapi kognitif yang secara spesifik digunakan pada individu yang ingin bunuh diri. CT-SP adalah psikoterapi singkat dan berbasis bukti yang bertujuan mengurangi risiko bunuh diri pada individu berisiko tinggi dengan mengajarkan keterampilan kognitif dan perilaku untuk mengurangi ide bunuh diri dan mencegah upaya bunuh diri. CT-SP menunjukkan hasil yang menjanjikan untuk orang dewasa (Berk et al., 2004; Brown et al., 2005; Henriques et al., 2003), remaja (Stanley et al., 2009), dan remaja tunawisma (Slesnick et al., 2020). Studi menemukan bahwa CT-SP menyebabkan pengurangan $50 \%$ dalam upaya bunuh diri berulang dibandingkan dengan perawatan atau intervensi biasa (Brown et al., 2005). Meskipun efektivitas CT-SP telah terbukti, namun belum ada penelitian tentang hasil CT-SP pada pendekatan berbasis internet.
Intervensi berbasis internet sangat diperlukan saat ini, utamanya di saat pandemic COVID-19. Internet dapat digunakan sebagai alternatif untuk menghadapi keterbatasan untuk melakukan intervensi psikologis secara tatap muka. Intervensi berbasis internet telah diusulkan sebagai salah satu cara yang digunakan pada pengobatan yang efektif untuk ide bunuh diri (Witt et al., 2017). Hal ini dikarenakan teknologi digital sangat menarik bagi kaum muda. Selain itu, individu yang punya ide bunuh diri cenderung mencari bantuan secara daring daripada tatap muka (Wilks et al., 2018). Berdasarkan pemikiran di atas, penulis melakukan penelitian untuk mengetahui efektivitas terapi kognitif berbasis internet dengan pendekatan kelompok untuk pencegahan bunuh diri dalam mengurangi ide bunuh diri pada mahasiswa. Peneliti memilih pendekatan kelompok karena ini memungkinkan peneliti untuk menjalin hubungan yang terapeutik dengan lebih banyak subyek secara efektif. Penelitian ini diharapkan dapat menjadi upaya pencegahan bunuh diri sehingga bisa menekan laju kasus bunuh diri di kalangan mahasiswa.

\section{METODE PENELITIAN}

Penelitian

menggunakan pendekatan kuantitatif untuk mengetahui efektifitas intervensi Cognitive Therapy for Suicide Prevention (CT-SP) berbasis internet dengan pendekatan kelompok terhadap variabel ide bunuh diri. Desain penelitian yang digunakan adalah pretest posttest control group design. Kelompok perlakuan mendapatkan CT-SP berbasis internet melalui aplikasi pertemuan daring Zoom dan website 
suicide.lembarharapan.id

yang

dikembangkan oleh penulis berdasarkan modul CT-SP milik Wenzel et al., (2009). Sementara, kelompok kontrol tidak mendapat perlakuan.

Penelitian berlangsung selama September hingga November 2020. Sebelum dilakukan intervensi, peneliti menyeleksi partisipan dengan metode purposive samping dengan kriteria sebagai berikut: 1) mahasiswa usia dewasa awal (18-25 tahun), 2) berstatus sebagai mahasiswa aktif di Perguruan Tinggi Negeri atau Swasta, 3) memiliki akses internet dan email pribadi, 4) memiliki skor ide bunuh diri (berdasarkan SSI) $\geq 26$ dan skor depresi (berdasarkan BDI II) $\geq$ 39 (kategori ringan-sedang) untuk mempertimbangkan faktor keselamatan, dan 5) bersedia mengikuti seluruh rangkaian intervensi dengan mengisi informed consent.

Setelah dilakukan seleksi partisipan, peneliti melakukan screening dan wawancara kepada calon partisipan sebanyak 87 orang. Hasilnya didapatkan partisipan sejumlah 38 orang yang bersedia mengikuti penelitian yang dibagi menjadi 2 kelompok (masing-masing 19 orang). Dari jumlah tersebut, subyek yang terlibat dalam penelitian hingga sesi follow up berjumlah 14 orang dengan masingmasing kelompok terdiri dari 7 orang.

Penelitian menggunakan kuesioner untuk mengumpulkan data dengan skala ide bunuh diri yang diadaptasi dari Scale for Suicide Ideation (SSI, Beck et al., 1979). SSI adalah skala penilaian terdiri dari 19 item untuk mengukur tiga dimensi, yaitu active suicidal desire (12 item), persiapan (4 item) dan passive suicidal desire (3 item).
Lima item pertama SSI dianggap sebagai item skrining. Tiga dari item ini menilai keinginan untuk hidup dan keinginan untuk mati, dan dua item lainnya menilai keinginan untuk melakukan bunuh diri dengan metode aktif atau pasif. Jika responden melaporkan keinginan aktif atau pasif untuk bunuh diri, maka 14 item tambahan diberikan. Item-item ini menilai karakteristik pemikiran bunuh diri dan tindakan persiapan, seperti durasi dan frekuensi ide, kontrol atas upaya, jumlah pencegah, dan jumlah persiapan aktual untuk upaya yang direncanakan. Setiap item SSI terdiri dari tiga opsi yang dinilai sesuai dengan intensitas ide bunuh diri pada skala 3 poin, mulai dari 0 hingga 2 . Skor per-item dijumlahkan untuk menghasilkan skor total 0-38. SSI membutuhkan waktu sekitar 10 menit.

Intervensi CT-SP diberikan dengan mengadaptasi manual terapi yang dikembangkan oleh Amy Wenzel, Gregory K. Brown, dan Aaron T. Beck pada tahun 2009. CT-SP adalah intervensi psikososial yang ditargetkan untuk memberikan keterampilan dalam menganalisa dan memodifikasi skema dan proses kognitif yang terkait dengan krisis bunuh diri, serta memodifikasi kerentanan faktor resiko yang memainkan peran sentral dalam krisis bunuh diri.

Intervensi berlangsung dalam empat pertemuan, yaitu 1) sesi identifikasi pemicu dan tanda peringatan untuk krisis bunuh diri dan pengembangan bagan konseptualisasi kasus kognitif, 2) sesi pengajaran keterampilan strategi coping kognitif, afektif dan perilaku, 3) sesi peninjauan keterampilan yang telah dipelajari dan guided imagery relapse 
untuk menilai kesiapan partisipan untuk mengakhiri terapi, dan 4) sesi follow up setelah satu bulan pasca intervensi.

Setiap pertemuan berlangsung selama 120 menit melalui aplikasi pertemuan daring Zoom dan website. Metode intervensi yang digunakan seperti ceramah, diskusi kelompok, role play, tugas pekerjaan rumah dan praktik penerapan keterampilan strategi coping. Materi meliputi penilaian faktor resiko bunuh diri, rencana keselamatan, bagan konseptialisasi kasus konitif, keterampilan coping kognitif, perilaku, dan afektif, dan relapse prevention protocol.

Hasil intervensi diukur dengan melakukan ujibeda terhadap kelompok perlakuan dan kelompok kontrol, yakni membandingkan gain score pada skala SSI. Teknik analisa data adalah independent $t$ test dengan menggunakan software SPSS edisi 21.

\section{HASIL DAN PEMBAHASAN}

Perbandingan hasil pretest dan posttest pada kelompok perlakukan dan kelompok kontrol dapat dilihat pada grafik berikut:

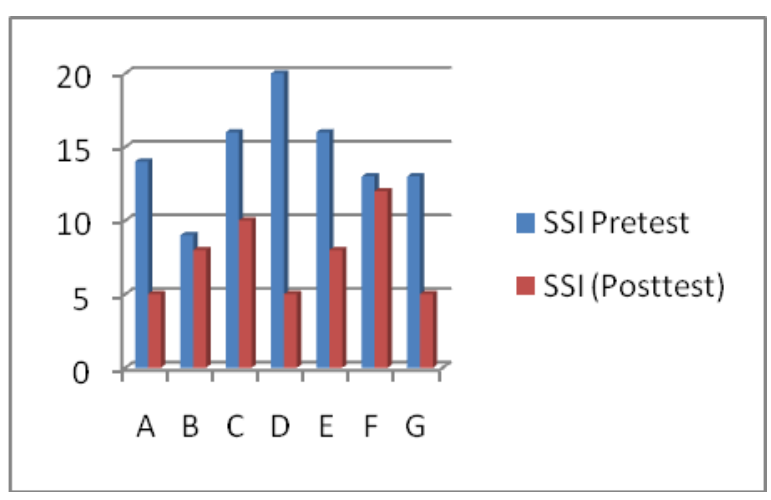

Gambar 1.Grafik Pretest dan Posttest Kelompok Eksperimen

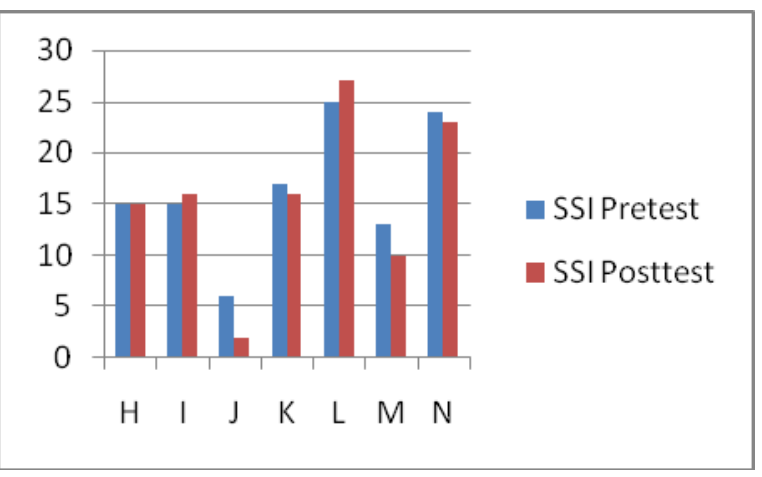

Gambar 2.Grafik Pretest dan Posttest Kelompok Kontrol

Tabel 1.Hasil Uji Independent Sample T-Test

\begin{tabular}{llcc}
\hline Skor & t & Df. & $\begin{array}{l}\text { Sig. (2 } \\
\text { tailed) }\end{array}$ \\
\hline $\begin{array}{l}\text { Gain score } \\
\text { (posttest-pretest) }\end{array}$ & 2.985 & $\mathrm{~L} 2$ & 011 \\
\hline
\end{tabular}

Berdasarkan tabel 1, nilai signifikansi menunjukkan bahwa ada perbedaan yang bermakna pada skor ide bunuh diri antara kelompok eksperimen dan kelompok kontrol sebelum dan sesudah diberikan intervensi. Perbedaaan ini muncul dikarenakan kelompok eksperimen mendapatkan perlakuan berupa intervensi Cognitive Therapy for Suicidal Prevention (CT-SP) berbasis internet, sedangkan kelompok kontrol tidak diberikan perlakuan.

Tabel 2.Hasil Perhitungan Effect Size

\begin{tabular}{ccc}
\hline Cohen's d & Eksperimen & Kontrol \\
\hline 1.595275 & Mean & $\begin{array}{l}\text { Standard } \\
\text { deviation }\end{array}$ \\
\hline & -6.86 & 4.880 \\
\hline
\end{tabular}

Table 2 menunjukkan nilai effectsize intervensi sebesar 1.595275. Nilai ini tergolong dalam kategori efektivitas besar (Cohen, 1988, dalam Rice \& Harris, 2005). Dengan demikian, dapat disimpulkan bahwa intervensi CT-SP berbasis internet dengan pendekatan kelompok memberikan 
efek yang besar terhadap penurunan ide bunuh diri pada mahasiswa.

Dari hasil penelitian di atas, dapat dikatakan bahwa intervensi CT-SP berbasis internet dengan pendekatan kelompok efektif dalam menurunkan ide bunuh diri pada mahasiswa. Hasil ini menambah bukti empiris mengenai efektivitas CT-SP sebagaimana hasil dari beberapa penelitian lainnya, seperti Berk et al., (2004), Brown et al., (2005), Henriques et al., (2003), Wenzel et al., (2009), Stanley et al., (2009), Wenzel \& Jager-Hyman (2012) dan Slesnick et al., (2020).

Hasil penelitian dapat dikaitkan dengan dinamika perubahan psikologis partisipan yang terjadi saat intervensi. Partisipan mengalami keadaan disorientasi kognitif sebelum ide bunuh diri muncul. Mereka memiliki keyakinan inti, seperti "Saya tidak berharga", "Saya gagal", "Saya tidak tahan lagi", "Saya tidak bisa mengatasi masalah", "Saya selalu salah", dan "Segalanya tidak akan menjadi lebih baik". Keyakinan inti tersebut muncul berkejarkejaran dengan disertai dengan kegelisahan akut. Proses kognitif ini pada akhirnya mengarahkan pada skema persepsi tak tertahankan dan keputusasaan serta fiksasi perhatian yang membuat mereka berfokus bahwa bunuh diri adalah solusi untuk permasalahan mereka.

Skema-skema yang relevan dengan bunuh diri yang muncul pada partisipan dapat dikaitkan dengan motivasi bunuh diri. Mereka melaporkan bahwa ingin mengakhiri hidup untuk mengubah atau memperbaiki lingkungan, utamanya terkait dengan relasi dengan orang tua dan ingin mengakhiri rasa sakit, penderitaan dan kesedihan karena pengalaman-pengalaman di masa lalu. Motivasi ini mengalami perubahan pada sesi intervensi karena partisipan menemukan solusi lain untuk memperbaiki hubungan dan mengatasi rasa sakit atas pengalaman-pengalaman di masa lalu.

Kesadaran atas adanya faktor protektif dan faktor resiko yang dimiliki, membantu partisipan untuk menyusun bagan konseptualisasi kasus dan menetapkan beberapa strategi coping yang bisa membantu mengurangi faktor resiko dan mengatasi ide bunuh diri. Beberapa etiologi yang terkait dengan faktor resiko yang ditemukan adalah fungsi hubungan keluarga yang bermasalah, permasalahan dalam hubungan pertemanan dan percintaan, permasalahan akademis, masalah keuangan. Selain itu, partisipan juga melaporkan faktor resiko lain seperti ketidakmampuan dalam meregulasi afeksi, depresi terhadap masa depan, dan pengalaman traumatis atau stressful life events.

Pengalaman traumatis atau stressful life events yang dilaporkan oleh partisipan meliputi kehilangan orang tua dan kerabat dekat karena kematian, konflik dengan teman dekat, menjadi korban revenge porn dari mantan pacar, pengalaman pelecehan seksual, perceraian orang tua, dan menjadi korban bullying di masa lalu. Pengalaman traumatis ini berinteraksi dengan faktor resiko dan variabel psikologis yang terkait dengan bunuh diri, seperti perasaan putus asa, tidak mampu memecahkan masalah dan perfeksionisme.

Strategi coping yang banyak dipilih untuk diterapkan selama intervensi antara lain daftar aktivitas menyenangkan, daftar dukungan sosial, imagery masa depan, identifikasi alasan untuk hidup, dan keterampilan memecahkan masalah. 
Strategi coping yang mengandung aspek kognisi, emosi dan perilaku ini membantu partisipan dalam mengatasi pengalaman krisis sehingga ide bunuh diri menjadi berkurang.

Hasil penelitian juga menemukan bahwa tidak ada perbedaan signifikan pada skor ide bunuh diri antara partisipan perempuan dan laki-laki. Penemuan ini berbeda dengan hasil survei dari studi Cheung \& Dewa (2006) yang menemukan bahwa depresi dan ide bunuh diri ditemukan lebih tinggi pada siswa perempuan jika dibandingkan dengan siswa laki-laki.

Dalam konteks online intervention, hasil penelitian ini juga menambah bukti efikasi dari intervensi berbasis daring terkait bunuh diri dengan pendekatan kognitif-perilaku. Penelitian lain juga meneliti tentang intervensi berbasis internet yang menargetkan ide bunuh diri, misalnya Mishara dan Kerkhof (2013), Hatcher (2013), Jacob et al (2014), Kerkhof \& van Spijker (2016), Hetrick, et al (2017), Leavey \& Hawkins (2017), dan Büscher et al (2020). Dengan demikian, internet dapat digunakan sebagai upaya alternatif dalam mengurangi ide atau upaya bunuh diri.

Penelitian ini masih memiliki keterbatasan. Jumlah subyek penelitian perlu diperbesar sehingga data demografis menjadi lebih beragam. Selain itu, ada kemungkinan terjadi sampling bias, yaitu subyek yang berpartisipasi dalam online screening mungkin berbeda dengan subyek yang direkrut dengan metodologi yang menggunakan offline screening. Kondisi pelaksanaan intervensi secara daring juga memiliki beberapa keterbatasan, misalnya sangat tergantung dengan ketersediaan dan kekuatan jaringan internet. Ketidakstabilan jaringan internet dapat mempengaruhi proses penyampaian materi saat intervensi sehingga perlu diantisipasi. Kesulitan teknis juga perlu menjadi perhatian utama karena mungkin dapat mengganggu proses pernyampaian materi. Terakhir, perlu adanya pelatihan untuk memastikan kompetensi terapis atau fasilitator dalam memberikan psikoterapi online. Terapis perlu menguasai kompetensi terkait teknologi dan kompetensi terapeutik khusus untuk pengaturan online sehingga tidak terjadi kesalahpahaman dan miskomunikasi demi mencapai interaksi yang terapeutik dalam intervensi klinis.

\section{SIMPULAN}

Ide bunuh diri merupakan masalah kesehatan mental yang serius di kalangan mahasiswa, namun hanya sedikit intervensi psikososial telah dikembangkan secara khusus untuk menargetkannya. Kesimpulan dari penelitian ini menunjukkan bahwa Cognitive Therapy for Suicide Prevention (CT-SP) berbasis internet dengan pendekatan kelompok efektif dalam mengurangi ide bunuh diri pada mahasiswa. Subyek penelitian mengalami pengurangan ide bunuh diri melalui tiga proses: (1) menganalisa faktor resiko dan faktor protektif yang terkait dengan pengalaman krisis munculnya ide bunuh diri; (2) mengidentifikasi dan melakukan rekontruksi kognitif dengan mengubah core belief negatif menjadi positif; (3) menerapkan rencana keselamatan dan strategi coping.

\section{DAFTAR PUSTAKA}

Arnett, J. J. (200o). Emerging adulthood: A theory of development from the late teens through the twenties. American Psychologist, 55(5), 
469-48o. https://doi.org/10.1037/ooo3o66X.55.5.469

Arria, A. M., O’Grady, K. E., Caldeira, K. M., Vincent, K. B., Wilcox, H. C., \& Wish, E. D. (2009). Suicide ideation among college students: A multivariate analysis. Archives of Suicide Research, 13(3), 230-246. https://doi.org/10.108o/13811110903044351

Beck, A. T., Kovacs, M., \& Weissman, A. (1979a). Assessment of suicidal intention: The Scale for Suicide Ideation. Journal of Consulting and Clinical Psychology, 47(2), 343-352. https://doi.org/10.1037//o022-006x.47.2.343

Beck, A. T., Kovacs, M., \& Weissman, A. (1979b). Assessment of suicidal intention: The Scale for Suicide Ideation. Journal of Consulting and Clinical Psychology, 47(2), 343-352. https://doi.org/10.1037/0022-0o6X.47.2.343

Berk, M. S., Henriques, G. R., Warman, D. M., Brown, G. K., \& Beck, A. T. (2004). A cognitive therapy intervention for suicide attempters: An overview of the treatment and case examples. Cognitive and Behavioral Practice, 11(3), 265-277. https://doi.org/10.1016/S10777229(04)80041-5

Brown, G. K., Ten Have, T., Henriques, G. R., Xie, S. X., Hollander, J. E., \& Beck, A. T. (2005). Cognitive Therapy for the Prevention of Suicide Attempts. Jama, 294(5), 563. https://doi.org/10.1001/jama.294.5.563

Cheung, A. H., \& Dewa, C. S. (2006). Canadian Community Health Survey: Major Depressive Disorder and Suicidality in Adolescents L'Enquête sur la santé dans les collectivités canadiennes : trouble dépressif majeur et tendance au suicide chez les adolescents. In HEALTHCARE POLICY (Vol. 2, Issue 2).

Downs, M. F., \& Eisenberg, D. (2012). Help seeking and treatment use among suicidal college students. Journal of American College Health, 6o(2), 104-114. https://doi.org/10.108o/o7448481.2011.619611

Harris, T. L., \& Molock, S. D. (2000). Cultural orientation, family cohesion, and family support in suicide ideation and depression among African American college students. Suicide \& Life-Threatening Behavior, 30(4), 341-353. https://doi.org/10.1111/j.1943278X.200o.tbo110o.X

Henriques, G., Beck, A. T., \& Brown, G. K. (2003). Cognitive therapy for adolescent and young adult suicide attempters. American Behavioral Scientist, 46(9), 1258-1268. https://doi.org/10.1177/ooo2764202250668
Hunt, J., \& Eisenberg, D. (2010). Mental Health Problems and Help-Seeking Behavior Among College Students. Journal of Adolescent Health, 46(1), 3-10. https://doi.org/10.1016/j.jadohealth.2009.08. oo8

Jobes, D. A., Au, J. S., Siegelman, B. A. A., \& Address, B. A. (2015). Psychological Approaches to Suicide Treatment and Prevention. https://doi.org/10.1007/s40501015-0064-3

Klonsky, E. D., May, A. M., \& Saffer, B. Y. (2016). Suicide, Suicide Attempts, and Suicidal Ideation. Annual Review of Clinical Psychology, https://doi.org/10.1146/annurev-clinpsy021815-093204

Kompas Online. (2019). "2o Persen Mahasiswa di Bandung Berpikir Serius untuk Bunuh Diri..."

Lemme, B. H. (1995). Development in adulthood. Needham Heights, MA;: Allyn and Bacon

Rice, M. E., \& Harris, G. T. (2005). Comparing Effect Sizes in Follow-Up Studies: ROC Area, Cohen's d, and r. Law and Human Behavior, 29(5), 615-620. https://doi.org/10.1007/s10979-005-6832-7

Sarwono, S. (2012). Psikologi Remaja. PT Raja Grafindo Persada.

Slesnick, N., Zhang, J., Feng, X., Wu, Q., Walsh, L., \& Granello, D. H. (2020). Cognitive Therapy for Suicide Prevention: A Randomized Pilot with Suicidal Youth Experiencing Homelessness. Cognitive Therapy and Research, 44(2), 402-411. https://doi.org/10.1007/s106o8-019-10068-1

Stanley, B., Brown, G., Brent, D. A., Wells, K., Poling, K., Curry, J., Kennard, B. D., Wagner, A., Cwik, M. F., Klomek, A. B., Goldstein, T., Vitiello, B., Barnett, S., Daniel, S., \& Hughes, J. (2009a). CognitiveBehavioral Therapy for Suicide Prevention (CBT-SP): Treatment Model, Feasibility, and Acceptability. Journal of the American Academy of Child and Adolescent Psychiatry, 48(10), 1005-1013. https://doi.org/10.1097/CHI.obo13e3181b5db fe

Stanley, B., Brown, G., Brent, D. A., Wells, K., Poling, K., Curry, J., Kennard, B. D., Wagner, A., Cwik, M. F., Klomek, A. B., Goldstein, T., Vitiello, B., Barnett, S., Daniel, S., \& Hughes, J. (20ogb). CognitiveBehavioral Therapy for Suicide Prevention (CBT-SP): Treatment Model, Feasibility, and Acceptability. Journal of the American 
Mariyati, P., \& Hamidah. Group Cognitive Therapy For Suicide Prevention Berbasis Internet

\author{
Academy of Child and Adolescent \\ Psychiatry, $\quad 48(10)$. \\ https://doi.org/10.1097/CHI.obo13e3181b5db \\ $\mathrm{fe}$
}

Tarter, R. E., Kirisci, L., Reynolds, M., \& Mezzich, A. (2004). Neurobehavior disinhibition in childhood predicts suicide potential and substance use disorder by young adulthood. Drug and Alcohol Dependence, 76(SUPPL.). https://doi.org/10.1016/j.drugalcdep.2004.08 .006

Wenzel, A., \& Beck, A. T. (2008). A cognitive model of suicidal behavior: Theory and treatment. Applied and Preventive Psychology, $\quad 12(4)$. https://doi.org/10.1016/j.appsy.2008.05.001

Wenzel, A., Brown, G. K., \& Beck, A. (2009). Cognitive Therapy for Suicidal Patients: Scientific and Clinical Applications.

Wenzel, A., \& Jager-Hyman, S. (2012). Cognitive Therapy for Suicidal Patients: Current Status. The Behavior Therapist, 35(7), 121130.

http://www.ncbi.nlm.nih.gov/pubmed/263 88663\%oAhttp://www.pubmedcentral.nih.g ov/articlerender.fcgi?artid=PMC4574874

Wilks, C. R., Coyle, T. N., Krek, M., Lungu, A., \& Andriani, K. (2018). Suicide Ideation and Acceptability Toward Online Help-Seeking. Suicide and Life-Threatening Behavior, 48(4), 379-385. https://doi.org/10.1111/sltb.12356

Witt, K., Spittal, M. J., Carter, G., Pirkis, J., Hetrick, S., Currier, D., Robinson, J., \& Milner, A. (2017). Effectiveness of online and mobile telephone applications ('apps') for the self-management of suicidal ideation and self-harm: A systematic review and meta-analysis. BMC Psychiatry, 17(1). https://doi.org/10.1186/s12888-017-1458-o 